\title{
¿Hacia qué fines nos orientan los textos de autoayuda?: Una reflexión desde el concepto foucaultiano de gobernabilidad
}

\author{
Towards what aims do the self-help texts orientate us?: \\ A reflection from the foucauldian concept of Governability
}

\author{
ROSARIO RUIZ CASTRO
}

IES Padre Manjón (Granada)

RESUMEN. La abrumadora presencia de los textos de autoayuda en la producción editorial de las últimas décadas invita a reflexionar no sólo sobre las necesidades a las que estos discursos intentan responder, sino también sobre los objetivos hacia los que orientan el comportamiento y las actitudes del individuo contemporáneo. En este trabajo abordamos dicha reflexión desde un marco teórico foucaultiano, considerando que los textos de autoayuda caen bajo el dominio de las "tecnologías del yo" y que su función puede interpretarse a la luz del concepto de gobernabilidad. Este concepto entraña la relación entre tecnologías del poder y tecnologías del yo que nos permite comprender el sentido en que el individuo aparece como gobernable, y permite también esclarecer el contacto que las ciencias psicológicas y psiquiátricas mantienen con las finalidades de la racionalidad política vigente.

Palabras clave: textos de autoayuda; tecnologías del yo; gobernabilidad; discurso psicoterapéutico; racionalidad política.
ABSTRACT. The overwhelming presence of self-help books in the editorial production of recent decades prompts us to reflect not only on the needs these discourses attempt to fulfill, but also on the objectives to which they lead the behavior and attitudes of the contemporary individual. In this article we tackle such reflections using a foucauldian theoretical framework, by considering that self-help books fall under the domain of "technologies of the self", and that their function can be interpreted in the light of the concept of governability. This concept concerns the relationship between technologies of power and technologies of the self allowing us to understand the sense in which the individual appears as governable, and it also permit us to clarify the contact point that psychological and psychiatric sciences have with the aims of the current political rationality.

Key words: self-help books; technologies of the self; governability; psychotherapeutic discourse; political rationality. 


\section{Introducción}

Fue a partir de 1980 , y en torno al concepto de "tecnologías del yo", cuando Michel Foucault comenzó a orientar la problematización del sujeto en un sentido diverso al que había predominado en su obra hasta entonces. En El nacimiento de la clínica y en Las palabras y las cosas, había estudiado la constitución de la subjetividad en relación con el saber o con las técnicas discursivas; en Vigilar y castigar atendió a esta constitución en relación con el poder que se ejerce mediante técnicas de dominación; pero será en el curso de la tarea iniciada con su Historia de la sexualidad, cuando Foucault se interese por cómo se constituye el sujeto a través de prácticas reguladas mediante las cuales el propio sujeto ejerce un dominio sobre sí mismo. Es en este último contexto donde las "tecnologías del yo" quedan definidas como aquellas "que permiten a los individuos efectuar, por cuenta propia o con ayuda de otros, cierto número de operaciones sobre su cuerpo y su alma, pensamientos, conducta o cualquier forma de ser, obteniendo así una transformación de sí mismos con el fin de alcanzar cierto estado de felicidad, pureza o inmortalidad." (Foucault, 1990, 48). De este modo, la actividad filosófica entendida como "ontología histórica de nosotros mismos" (Foucault, 1999) orienta el análisis crítico de lo que somos hacia el dominio de la ética, y contempla al individuo en el proceso de su constitución como agente moral, sin olvidar la intrincación que el poder, el saber y la ética mantienen entre sí.

En el examen genealógico de estas tecnologías del yo o "prácticas de sí", rastre- adas en su devenir histórico desde la Antigüedad Clásica, fue donde Foucault vislumbró un espacio de libertad para el sujeto que le permite edificarse con cierta independencia de los dispositivos institucionales del poder y elaborar al mismo tiempo un ámbito desde el que es posible individualmente la resistencia. Sin embargo, en la primera conferencia de las tres que pronunció en Toronto en el año 1982, Foucault nos advertía contra el entusiasmo respecto a una cierta "cultura de sí mismo" propiciada por las actitudes estéticas y políticas contemporáneas, advertencia ésta que invita a la reflexión sobre el modo en que nos constituyen las modernas tecnologías del yo. La sospecha de que el "sí mismo" al que estas tecnologías se dirigen no sea agente de emancipación, sino un objeto dado de antemano que estamos obligados a conocer, sería el núcleo principal de una posible perspectiva crítica ante la máscara de libertad con que parecen seducirnos las tecnologías del self en nuestro tiempo, tecnologías emanadas del cuerpo teórico de las ciencias que interaccionan con las formas vigentes del poder político.

La pregunta que aquí nos formulamos sobre los textos de autoayuda se adscribe a esta precaución crítica insinuada por Foucault y tiene en vista las aportaciones que diversos autores inspirados por los métodos foucaultianos han realizado al análisis del presente de nuestra subjetividad, análisis que, según se deprende de sus últimos escritos, estaba en el ánimo del filósofo francés acometer.

Puesto que actualmente, como en otras épocas, es posible encontrar textos concebidos al efecto de manuales de guía y 
orientación de la conducta en distintos terrenos, es preciso señalar que, al referirnos al fenómeno de la autoayuda en este trabajo, aludimos a un tipo de literatura cuya aparición se sitúa a finales de los años 70, - con su principal foco de producción en Estados Unidos-, que incorpora principalmente la herencia recibida de los discursos de las ciencias psicológica y psiquiátrica, y cuya exitosa expansión se sostiene desde los años 80 hasta nuestros días. "Hemos sido inundados- escribe Ian Hacking- por manuales que ofrecen técnicas de autosuperación. Una genealogía de la ética sería un estudio de lo que estas técnicas son realmente y de cómo las usamos sobre nosotros mismos." (Hacking, 2002, 115). Si reparamos en la principal fuente teórica que nutre estos discursos de autoayuda, la reflexión sobre este fenómeno debe implicar una crítica al intento de constituir una ética del yo a partir de lo que las ciencias psicológicas dicen que es el yo. Ello supone al mismo tiempo reconocer la hegemonía social que en nuestra época ha alcanzado "lo psicoterapéutico", denominación con la que Nikolas Rose (1999) se refiere al conjunto de prácticas y conocimientos, derivados de las ciencias psicológica y psiquiátrica, que han llegado a erigirse en claves comprensivas y organizadoras de la vida social hasta el punto de que sea posible hablar de psicologización de la sociedad.

Ahora bien, aquí nos proponemos analizar específicamente el sentido en que se orienta la eficacia de estos textos adoptando como instrumento analítico el concepto foucaultiano de gobernabilidad, que permite comprender cómo el sujeto se constituye en la superficie de contacto en- tre las tecnologías de gobierno y las tecnologías del yo. Este análisis requiere contemplar la subjetividad como elemento participante en la dinámica del saber y del poder, y requiere distinguir en esta dinámica las tecnologías que actúan sobre los otros de las tecnologías que actúan sobre uno mismo. Partiendo, pues, de un marco teórico netamente foucaultiano, la respuesta a la pregunta formulada en este artículo incorpora la perspectiva de autores que han tomado el relevo de Foucault en el trayecto que recorre nuestro tiempo. Estas aportaciones nos permiten advertir las conexiones de la construcción del conocimiento psicológico y de la constitución de la subjetividad con una determinada racionalidad política. Es en esta dinámica relacional donde hemos creído conveniente plantear la pregunta que en lo sucesivo trataremos de responder.

El orden expositivo en el desarrollo de esta respuesta parte del análisis foucaultiano que nos permite comprender la subjetividad como objetivo del poder político, y continúa elaborando algunas zonas de contacto entre el discurso psicoterapéutico y la racionalidad política vigente. En estas zonas de contacto situaremos a los textos de autoayuda como elementos adscritos a "lo psicoterapéutico", y como orientados a la misma eficacia de tal conjunto de conocimientos y prácticas que funciona como tecnología de gobierno. Por último, atenderemos con algún detenimiento a un texto de autoayuda -que hoy puede considerarse como uno de los pioneros y representativos de la ingente producción posterior- con objeto de ilustrar las conclusiones a que conduce nuestro análisis. 


\section{La subjetividad como objetivo del poder político}

Más que ningún otro momento anterior de la historia, el período ilustrado nos enseñó, como dice Foucault, el poder político que puede alcanzar la razón. Así que, desde el momento en que la sociedad se organiza políticamente y se consolidan los Estados Modernos, la filosofía incluye entre sus funciones una actitud vigilante respecto a los abusos del poder que ejerce la racionalidad política de turno, pues el ejercicio del poder no se dice de la razón en general sino de un tipo concreto de racionalidad.

A pesar de la tendencia centralizadora del poder que han exhibido los Estados desde su constitución en Europa, pueden ponerse en evidencia, pensaba Foucault, cierto tipo de transformaciones en las relaciones de poder características de las sociedades modernas que parecen operar en sentido contrario a esa tendencia centralizadora, relaciones en las que las técnicas del poder se orientan hacia los individuos con el fin de gobernarlos de manera constante y permanente. Esta tendencia responde a una caracterización del poder como "individualizador", o "individualizante", un poder que encuentra un modelo de referencia en el pastorado, cuya finalidad consiste en salvaguardar la vida de un grupo de individuos mediante la atención individual a cada miembro del rebaño. El modelo de poder representado por la centralización estatal responde, en cambio, al esquema ciudad-ciudadanos, según el cual gobernar es formar y asegurar la unidad del Estado: "El problema político es el de la relación entre lo uno y la multitud en el marco de la ciudad y de sus ciudadanos. El problema pastoral concierne a los individuos" (Foucault 1990,110)

Foucault encuentra estos modelos de poder representados en los textos antiguos. Grecia privilegió el modelo político, pero el cristianismo afianzó en Occidente las formas de concebir las relaciones políticas propias del modelo pastoral. Esta historia nos interesa en la medida en que las democracias occidentales son una combinación de estos dos juegos de poder: el que opera en la unidad que representa el marco jurídico del Estado y el que se encarga de cuidar y mejorar la vida de todos y cada uno de los individuos (Foucault, 1990, 111). Este último modelo que responde a la figura del pastor es el que nos permite comprender el poder "individualizador" o subjetivizante que adquieren los discursos del conocimiento experto en manos de los aparatos del poder político, pues esa relación hace posible gobernar individuos preocupándose por conocerlos. El pastor, para cumplir con sus funciones, no sólo debe atender las necesidades materiales de cada miembro del grupo y satisfacerlas, así como saber qué hace cada uno de ellos, sino también "conocer sus pecados secretos" o "saber lo que sucede en el alma de cada uno". Análogamente, las instituciones sociales que se reparten el ejercicio del poder político requieren conocimiento de diversos tipos sobre los individuos cuyo gobierno tienen encomendado. Cuando esos conocimientos son traducidos a los códigos que permiten al poder político hacer cálculos y trazar sus estrategias, el conocimiento adopta la forma de una tecnología: la tecnología de poder. 
Este tipo de tecnologías, -uno de los cuatro tipos identificados por Foucault-, es capaz de "producir" sujetos, en el sentido de constituirlos o componer la verdad de lo que son, cuando consigue entrar en contacto con los individuos y generar tecnologías del yo. Tal contacto se entiende como los cambios que las tecnologías de poder producen en la conducta del sujeto, no sólo en lo que se refiere al repertorio de sus habilidades sino también en sus actitudes. Este es el contenido de la noción de gobernabilidad, que Foucault define expresamente como el contacto entre las tecnologías de dominación de los demás y las referidas a uno mismo (Foucault, 1990, 49). Esta relación permite comprender que la naturaleza fundamental del poder no es violencia o consenso implícitamente prorrogado, pues, aunque éstos son instrumentos del poder o resultados suyos, en sí mismo el ejercicio del poder "es un conjunto de acciones sobre acciones posibles; opera en el campo de posibilidad o se inscribe en el comportamiento de los sujetos actuales: incita, seduce, facilita o dificulta; (...) siempre es una manera de actuar sobre un sujeto actuante o sobre sujetos actuantes, en tanto que son susceptibles de actuar. Un conjunto de acciones sobre otras acciones." (Foucault, 1988, 238239). Si el ejercicio del poder consiste en "conducir las conductas y en arreglar las posibilidades" (Foucault, 1988, 239), la noción de "gobierno" queda circunscrita a un juego de relaciones más específico que el propio de la gestión de los Estados, de modo que, en este sentido, "gobernar es estructurar el posible campo de acción de los otros" (Foucault, 1988, 239)

Analizar las diversas formas en que dichas relaciones de poder constituyen la subjetividad históricamente, y conectan al sujeto, a través de tecnologías de gobierno, con las racionalidades políticas vigentes, es construir una ontología histórica del sujeto. Desde esta perspectiva, la constitución del sujeto se hace en torno a criterios que son en realidad los fines y objetivos de una racionalidad política concreta, fines fundamentados en principios sobre cómo entender la justicia, la libertad, etc. Cada racionalidad política se sirve de ciertos medios ajustados a esos propósitos; por tanto, una racionalidad política no se construye solamente en torno a una concepción de la naturaleza humana proporcionada por los argumentos de los filósofos, sino que genera sus propias tecnologías de gobierno, a partir de discursos que producen y regulan las prácticas sociales e individuales de las personas.

Nos interesa, desde este contexto conceptual, establecer diferencias históricas clave, en el ejercicio del poder por parte del Estado, que permitan comprender el lugar preeminente alcanzado en las sociedades contemporáneas por el discurso psicoterapéutico y los instrumentos que incorpora como práctica discursiva. La diferencia de obligada mención en ese sentido apunta a las nuevas formas de poder que se inauguran en el siglo XIX, cuando el control de las poblaciones deja de realizarse mediante las tecnologías represivas, coercitivas y policiales que localizan el poder en lugares concretos como los centros de confinamiento, y se dispersa en un conjunto de prácticas que nos constituyen en la forma de sujetos morales, sujetos de deseo y objetos de la ciencia. (Sáez, 2004, 7) 
La noción de "disciplina” y el modo en que se administra, resultan cuestiones fundamentales para entender cómo se transforma la conexión entre las reglas de la racionalidad política y las formas de autogobierno. Esto es, el desarrollo tardío que experimenta la democracia en las sociedades modernas depende de que la disciplina, lejos de localizarse en centros concretos, llegue a formar parte de la estructura mental de los individuos. Se entiende entonces, para ese propósito, que sea necesario constituir cierto tipo de sujetos, capaces de responsabilizarse de sus acciones, y en los cuales la antigua constricción de la acción policial sea traducida a control interno de la conducta. Esta transformación que va del poder sobre el yo, ejercido desde instancias externas, al poder internalizado, a instancias del propio autodominio, refleja la influencia del neoestoicismo en las doctrinas que sirvieron de base a las nuevas formas de poder y de administración. (Oestreich, G. 2008, Cf. Rose, 1999, 226)

La sutileza de este modo de administrar el poder sugiere que es posible ejercer un poder individualizante, que instala el mecanismo de control en el alma del sujeto, “desde la libertad". En el ejercicio de esta clase de poder el auge del discurso psicoterapéutico desempeña una función clave, que sólo se entiende en conexión con una profunda transformación en la racionalidad política y en las técnicas de gobierno que le acompañan, a saber, la que convierte a la subjetividad misma en punto de mira primordial de los sistemas políticos. Si bien toda racionalidad política, desde el origen de los Estados modernos, ejerce un poder individualizante sobre los sujetos, mediatizado por tecnologías de gobierno de carácter represor o coercitivo, la novedad, coincidente con el auge de lo psicoterapéutico a partir de la II Guerra Mundial, estriba en que las racionalidades políticas que se han sucedido desde entonces incorporan a sus finalidades y aspiraciones la subjetividad misma, esto es, las capacidades de los sujetos, sus deseos y sus formas de pensamiento. "El 'alma' del ciudadano ha entrado directamente en el discurso político y la práctica del gobierno" (Rose, 1999, 4). Digamos que, en este caso, la racionalidad política escoge al individuo como medio con que solventar las crisis y asegurar la estabilidad, induciéndolo a modelar por sí mismo sus capacidades y actitudes en consonancia con las demandas económicas y sociales que el Estado tiene que enfrentar. Pero, como es obvio, este poder subjetivador no se ejerce destruyendo la autonomía del sujeto, alienando su independencia a manos de tecnologías de gobierno y tecnologías del yo que mutilan sus potencialidades- como hizo el discurso psiquiátrico sobre la locura en los grandes encierros del siglo XVIII- sino que se ejerce de una forma constructiva $o$ plenamente constituyente, puesto que su finalidad es precisamente edificar un yo autónomo, que por medio de la autoinspección y la autoconciencia maximice sus capacidades.

El discurso de las ciencias psicológicas y psiquiátricas puede proveer los medios necesarios para el ejercicio de un poder semejante. Consiste precisamente en el tipo de conocimiento que la racionalidad política requiere para conformar tecnologías de gobierno que gobiernen a su vez la 
conducta individual. Así, por una parte las ciencias "psi" procuran, con las pruebas de inteligencia y personalidad, y con todos los instrumentos de diagnóstico y clasificación que producen, convenientemente formulados en registros numéricos, el tipo de estadística que necesita el gobierno para traducir el pensamiento subjetivo a un lenguaje estratégico de fuerzas calculables. Por otra parte, la psicoterapia proporciona el mecanismo de autoinspección exigible a los sujetos aptos para la vida en sociedades regidas por los principios democráticos de libertad y justicia, al mismo tiempo que asegura una intervención constante en lo más recóndito del alma humana. He aquí una de las formas más sofisticadas en que el hombre deviene, según la expresión de Foucault, "animal de confesión".

Es importante advertir que la extensión de lo psicoterapéutico no es la de cualquier ámbito de conocimiento experto a disposición del poder estatal, como lo fueran otros discursos en la historia de las racionalidades políticas, pues el tipo de prácticas e instituciones que este discurso requiere para hacerse efectivo, produce lo que llama Rose una "gubernamentalización del Estado". Esto quiere decir que la profusa y extensa red de tecnologías adjuntas a lo psicoterapéutico ha constituido sus propias formas de autoridad, de modo que es sobre todo por disposición de los innumerables microcentros del poder que lo psicoterapéutico genera (trabajadores sociales, abogados, educadores, padres, policía, investigadores, etc., conformados a menudo en asociaciones y alianzas de estatuto diverso) como se producen los programas de actuación sobre la conducta de los individuos, mientras que el estado pocas veces gestiona directamente este poder con actuaciones propias. El estado gobierna, pues, "a distancia" a través de las tecnologías que desde esos micromundos institucionales se organizan y se ponen en marcha. Así, la versatilidad de las ciencias psicológicas, lejos de restar efectividad al conocimiento que las compone, permite ejercer su dominio en sectores tan amplios como diversos de la vida social. Esta misma capacidad que el conocimiento experto de la psyque tiene de penetrar todos los intersticios sociales, al mismo tiempo que los del alma, permite comprender que las relaciones entre el poder y la subjetividad no se reducen a la alternativa de reprimir o conceder libertad al individuo, sino que, mediante las prácticas de esta pericia psicológica, el poder político, "estimula la subjetividad" (Rose, 1999) en el sentido de promover la autoinspección y la autoconciencia y de modelar los deseos hacia la maximización de capacidades.

Los textos de autoayuda son, en este marco de acción estratégica diferida, un elemento de contacto entre los fines de la racionalidad política, el conocimiento experto de las ciencias psicológicas y las tecnologías del yo. Son producciones textuales menores derivadas de los textos estratégicos que el poder gubernamental produce en su propagación de la racionalidad política en que se inserta. Dichos textos estratégicos, -informes de comisiones investigadoras, manifiestos, regulación normativa de los ámbitos profesionales, del ejercicio de las ciencias de la salud, de las prestaciones sociales y la beneficencia, etc.- generan a su vez textos 
subordinados, como las columnas de opinión, documentos divulgativos, panfletos y propagandas diversas, entre los cuales los textos de autoayuda han ido haciéndose un hueco cada vez más autorizado y consistente. Ellos conforman un área de entrenamiento individual del sujeto en el tipo de habilidades y competencias que la racionalidad política prescribe y que las tecnologías emanadas de lo psicoterapéutico revisan, reformulan y ayudan a componer.

Con objeto de ubicar el auge de lo psicoterapéutico en sus marcos políticos precisos en el último siglo, y a fin de comprender los textos de autoayuda en relación con esos marcos, distinguiremos aquí dos racionalidades políticas diferentes.

\section{Textos de autoayuda y racionalidad politica neoliberal}

Los autores que intentan comprender el fenómeno de los textos de autoayuda en el contexto de una racionalidad política, y en conexión con un tipo de tecnologías de gobierno (Cruikshank, 1996; Rose, 1998 y 1999; Lupton, 1999; Abraham, 1990 y 2000; Ampudia de Haro, 2006; McGee, 2005; Luchtengberg y Bruno, 2006;...) reconocen la superficie de emergencia de este fenómeno en el cambio de diagrama de poder que tiene lugar a partir de los años 70 , período en puede trazarse aproximadamente la línea divisoria entre las sociedades disciplinarias y post-disciplinarias. En dicha década se habría producido una transformación en el mapa de las relaciones de poder que modifica significativamente el modo de entender las funciones gubernamentales. La aparición de una nueva etapa del capitalismo, propiciada por las crisis energéticas de los 70 (Luchtenbeg y Bruno, $2006,1)$ que dan lugar a nuevas tecnologías de producción (p.ej. el desarrollo del capital financiero con base informática), ocasiona lo que Foucault caracterizó como un "aparente repliegue de poder" en las funciones del Estado, que no puede mantener los costes sociales y económicos de la presencia que hasta entonces había mantenido. El Estado habría relajado el ejercicio de un poder disciplinario que se extiende, con formas que progresivamente delegarán en el individuo el ejercicio de la disciplina, hasta los últimos años de la racionalidad política welfarista, comúnmente conocida como "Estado del Bienestar". Esta racionalidad extendió a todo el orden social una serie de técnicas disciplinarias encaminadas a garantizar el bienestar general. Con esta perspectiva, la normalización y la prevención de riesgos son rasgos que identifican un esquema de poder basado en la integración y re-adaptación de los excluidos, y el tipo de disciplina que inculca en el sujeto esta racionalidad es la de un ser social, cuyos derechos y obligaciones han sido establecidos en un lenguaje de responsabilidad y solidaridad colectivas. (Rose, 1999, 227). Así, el sujeto pasivo de derechos y deberes constitucionales que era el ciudadano del siglo XIX se convierte en sujeto activo que contribuye a una política saludable para el conjunto de la sociedad. La seguridad social o la regulación del bienestar infantil son productos notorios de esta racionalidad. Pero en la década de los 50 a los 60 tiene lugar una transformación importante en estos esquemas, en el sentido de que los gobiernos limitan la actuación coercitiva de la ley a una serie de actividades intolerables 
en cuanto a sus repercusiones en el orden público, pero ya no se sienten compelidos a regular los deseos, los sentimientos o la moral de los individuos, que en lo sucesivo configuran sus opciones personales no por coerción de la legalidad estatal sino por la presión de la opinión pública y de la propia conciencia. El estado, como dice De Marinis (1998) se vuelve "miope" respecto a comportamientos que no le interesan y que tiende a pasar por alto.

El cuestionamiento del uso coercitivo del poder estatal tiene ya algunas manifestaciones expresas en los cincuenta; así el Informe del Comité de Infracciones Homosexuales y Prostitución de Londres de 1957 declara: "No es la función de la ley intervenir en la vida privada de los ciudadanos ni tratar de reforzar ningún patrón determinado de conducta." (Cf. Rose, 1999, 229). Paralelamente a los cambios que flexibilizan la regulación y enjuiciamiento de la conducta del individuo, brotan las críticas al Estado del Bienestar, como fomentador de una "cultura de dependencia" y promotor de la violación de libertades y derechos individuales. A principios de los años 90, las críticas en este sentido pueden resumirse en las siguientes (Ampudia de Haro, 2006, 67): a) El Estado de Bienestar coarta las libertades individuales. b) Es un modelo ineficaz e ineficiente. c) Impone trabas al libre desarrollo del mercado. d) Fomenta una tendencia congénita a la crisis fiscal debido al elevado gasto público. e) Fomenta el asistencialismo y una cultura de dependencia en el ciudadano. f) Es altamente improductivo, en comparación con la productividad y el dinamismo de la iniciativa empresarial privada.
La racionalidad política alternativa a la que es objeto de tales críticas empieza a consolidar unos principios cuya expresión teórica más afín es la del Neoliberalismo o "Liberalismo avanzado". Este modelo político elimina la planificación a largo plazo, modifica las concepciones del espacio y el tiempo en lo referente a la previsión de riesgos, desequilibrios o crisis que haya que enfrentar individual y colectivamente, y sustituye los férreos programas y controles gubernamentales respecto a la seguridad y la administración de servicios básicos por un modelo estimulador del consumo privado de dichos servicios. En este contexto, el buen ciudadano no es el ciudadano social que tiene en vista los intereses colectivos cuando se da a sí mismo las normas de comportamiento, sino un individuo cuya ciudadanía debe ser demostrada como capacidad de autogestionarse, al modo de libre ejercicio de elección personal entre una gama de opciones mercantilizadas. La forma en que se articula el concepto de "riesgo" es significativa de las políticas de esta racionalidad en lo que se refiere a esa capacidad de autogestión, pues la previsión y cálculo de los riesgos aplicados a las poblaciones es ahora también una obligación del individuo para consigo mismo. Deborah Lupton lo explica del siguiente modo: "El riesgo, desde la perspectiva foucaultiana, es una tecnología moral. (...) Las estrategias de gobernabilidad, expresadas en los estados neoliberales que emergieron en occidente en la última modernidad, incluyen estrategias (...) que implican la complicidad voluntaria de los individuos con los intereses y necesidades del estado. (...) la regulación y disciplina 
de los ciudadanos está dirigida hacia el individuo autónomo, autorregulado. (...) los individuos son sus propios policías, ejercen el poder sobre ellos mismos como sujetos normalizados en pos de sus mejores intereses y de libertad, interesados en la automejora, buscando felicidad y salud." (Lupton, 1999, 88)

La identidad personal es, en este marco, lo que expresa el ensamblaje entre las elecciones hechas por cada uno. La autodependencia, como un absoluto al que dirigir los esfuerzos en un sistema social que ya no se siente obligado a ofrecer garantías; la conquista del control interno, como antídoto emocional ante la angustia que produce la inminencia permanente de los cambios; el ocio como dominio de elección personal por excelencia con que el ciudadano es llamado a perpetuar la sociedad de consumo; la flexibilidad profesional y emocional del sujeto, en consonancia con la imprevisión de un "capitalismo flexible" (Richard Sennet, 2000; Luchtenberg y Bruno, 2006), son algunos de los rasgos que conforman el conjunto de valores (felicidad, autorrealización, autonomía,...) a los que se debe aspirar y el tipo de competencias psicológicas que es necesario entrenar (autorregulación, autocontrol, autoestima, asertividad,...), no como una suerte de lujo o sofisticación en el modelaje que cada cual hace de sí mismo, sino como un equipaje indispensable ante la amenaza de exclusión social.

Desde una lectura similar, Tomás Abraham (2000) habla de "autoestima tutelada", en referencia a la relación que se establece entre el concepto de autoestima y el "achicamiento" o la desaparición del
Estado de Bienestar. Esta relación apunta a una nueva estrategia por parte del Estado cuya intervención consiste en trazar un tejido entre las conductas antisociales y la valoración de sí a través del discurso de la autoestima. Puesto que la baja autoestima se relaciona con la desviación, la marginación y con el perfil psicológico que representa socialmente un peligro potencial, la "provisión" de autoestima puede entenderse como una tecnología para constituir al ciudadano en el ejercicio responsable de la ciudadanía y evitar el coste que el Estado ha de emplear en medidas correctoras una vez que la conducta antisocial se hace efectiva. En esta interpretación, Abraham se hace eco de los argumentos que Barbara Cruikshank (1996) aporta en un ensayo donde aplica a la autoestima conceptos foucaultianos. Según esta autora, el movimiento de la autoestima no deja a la política y al poder tal como estaban, sino que busca constituir un "estado de autoestima", una nueva política y un nuevo complejo de relaciones sociales: "[el movimiento de la autoestima] (...) promete repartir una tecnología de subjetividad que resolverá problemas sociales, desde el crimen y la pobreza a la desigualdad de género, promoviendo una revolución social, no contra el capitalismo, el racismo o la desigualdad, sino contra el orden del yo y el modo en que nos gobernamos a nosotros mismos." (Cruikshank, 1996, 231). El efecto que esta tecnología persigue en los individuos es el de la producción de ciertos tipos de "yoes", producción que, a juicio de Cruikshank, puede entenderse en el sentido que Ian Hacking acuña en el concepto de "inventar personas". Este tipo de "yoes" es la 
expresión, más que de una nueva forma de gobierno, de la sustitución del gobierno por el autogobierno ${ }^{2}$ a que aspira la promoción de la autoestima. Es claro que en los textos de autoayuda encuentra esta tecnología de gobierno un soporte productivo: "(...) un yo emerge, al enfrentarse, ante todo, con los textos, o con la narración y escritura de historias personales, una práctica que Steinem ${ }^{3}$ denomina $b i$ blioterapia."(Cruikshank, 1996, 233).

Esta avalancha de demandas, implicadas en la racionalidad política neoliberal en la forma de competencias que han de producirse en el individuo, es lo que da sentido a la centralidad del discurso psicoterapéutico como fuente de tecnologías de poder y de tecnologías del yo. Sin embargo, las psicoterapias, no reglamentadas estatalmente en un sistema de prestación global ${ }^{4}$, permanecen como parte de la oferta del mercado y son todavía un costoso producto de consumo que el individuo no siempre puede permitirse, por más que lo demanden la angustia y la ansiedad que a menudo le ocasionan las exigencias de la sociedad neoliberal, y por más que sea compelido a reconstituirse en torno a un orden de competencias que le permitan funcionar como se espera en lo que Rose (1999) denomina la "sociedad contractual del yo".

Los textos de autoayuda son, en este contexto, no sólo herramientas que el mercado pone a disposición del individuo inserto en una racionalidad política que demanda ciertas capacidades (Ampudia de Haro, 2006), sino tecnologías que constituyen un tipo de sujeto como obligado a ser libre y obligado a ser feliz, sujeto entrenado para la constante autoinspección, automonitorización y autoevaluación, según criterios que nos damos a nosotros mismos pero que otros formulan para nosotros. Son textos que forman parte de la estrategia trazada por las tecnologías del poder en tanto que a través de ellos se gobierna la conducta individual, o dicho de otro modo, revelan al individuo como gobernable por medio de tecnologías de sí mismo. Se trata, en efecto, de una promoción del autogobierno, pero entendida como provocación constante a la voluntad de entrenarse para una realidad social en que la estabilidad es ya un asunto anacrónico, y en que la compulsión en la búsqueda de la felicidad, más que un imperativo emancipador, es el anhelo de una especie de ortopedia o anestesia con que enfrentar las frecuentes crisis que son endémicas de este orden social. Los textos de autoayuda son un recurso a la mano cuyo masivo consumo da a entender que el individuo asume esta labor de hacerse cargo de sí mismo, confirmando esta lectura de la vida social y personal de nuestro tiempo. Así lo ve McGee en referencia a la sociedad americana: "La atracción por esta literatura es comprensible: el tremendo crecimiento de las publicaciones de autoayuda es paralelo a una tendencia general a la congelación de los salarios y la inestabilidad en las oportunidades de empleo (...) Los americanos muestran lo que algunos observadores sociales llaman una "nueva inseguridad" cuando se han acabado los stándares de familia y empleo. (...) En lugar de una red de seguridad social a los americanos se les ha ofrecido una lista tras otra de libros de autoayuda para estimular sus espíritus y mantenerse a flote en aguas sociales y 
económicas inexploradas. La red de autoayuda tiene sus propias trampas. (...) puede conducir a los trabajadores a un nuevo tipo de esclavitud: en un ciclo en que el yo no es mejorado sino indefinida y absurdamente sobrecargado". (McGee, 2005, 12)

\section{Descubriendo nuestras "zonas erróneas"}

Con objeto de ilustrar algunos aspectos de nuestro análisis, prestaremos atención a un texto de autoayuda. El texto en cuestión es el que lleva por título Tus zonas erróneas (Dyer, 1993), publicado por primera vez en 1976 en Estados Unidos, del se han sucedido las ediciones casi ininterrumpidamente desde entonces, y del que se han vendido más de treinta y cinco millones de ejemplares. Si elegimos este texto es porque tiene, a nuestro juicio, el mérito de haber trazado líneas paradigmáticas en la conformación del tipo de discurso de autoayuda que es objeto de reflexión en este artículo, y porque, contemplado retrospectivamente, presenta una temprana sensibilidad para captar la situación psicológica del sujeto ante las primeras avanzadas del neoliberalismo, que se acusan primeramente en la sociedad norteamericana. El texto no sólo inaugura un modelo de práctica privada de los principios de una corriente psicológica- la psicología humanística- sino que los aplica hábilmente a los "trastornos" de nuevo cuño que el momento social e histórico está gestando en las personas, y que se resumen en la desorientación, la sobrecarga de responsabilidades y la indefensión psicológica ante una maquinaria social que perfec- ciona sus engranajes a costa del abandono del individuo a su suerte y a su capacidad de buscar oportunidades por sí mismo.

El desarrollo de la obra gira en torno a los que, desde nuestra lectura, se revelan como puntos débiles de la estructura psíquica del individuo en contacto con la racionalidad política emergente. Como los remedios psicológicos propuestos son indicadores de los puntos conflictivos que requieren ayuda y tratamiento, un resumen de los mismos es suficientemente ilustrativo de en qué sentidos se considera necesaria la transformación. Siguiendo el contenido de la obra, pueden relacionarse al respecto los siguientes centros de atención:

1 Hacerse cargo de uno mismo, contando sólo con los propios medios, aptitudes, situación presente y la propia capacidad de elegir.

2. Quererse y aceptarse incondicionalmente: autoestima sin requisitos previos.

3. Deslegitimar y liberarse de la necesidad de aprobación: reconocer como inútil su rentabilidad psicológica.

4. Desvelar las influencias paralizantes del propio pasado como condicionamientos neuróticos.

5. Desactivar el poder de las emociones negativas, especialmente la culpa y la preocupación.

6. Abrirse a nuevas experiencias, eliminando el miedo a lo desconocido y desautorizando la necesidad de perfeccionamiento y planificación.

7. Promover la indiferencia ante el valor normativo de los convencionalismos: eliminar la estructura de 
"deberización" que brota de ellos.

8. Eliminar la demanda psicológica de justicia, como una fuente de sufrimiento inútil.

9. Desarrollar pautas de acción inmediata, centrando la intensidad vital en el momento presente y eliminando los aplazamientos de comportamientos deseados.

10. Conseguir la independencia, especialmente respecto a las fuentes de dependencia psicológica.

11. Eliminar la ira como reacción típica ante el miedo y la frustración.

Una mirada atenta a esta batería de objetivos sugiere el boceto de un perfil psicológico adecuado a las demandas de la "nueva inseguridad" que representa para el individuo la racionalidad política neoliberal. Lejos de representar el esquema de un modelo de persona perfeccionado en algún sentido ético o antropológico, estas estrategias están destinadas a conformar un tipo de sujeto que ya está implícitamente presupuesto en la trama social como condición necesaria de la no exclusión. Traducido esto mismo al lenguaje normativo, podría decirse que el fundamento de la libertad de prescribir para uno mismo ciertas normas de conducta y ciertos principios reguladores de la acción no tiene en este sujeto más apoyo que el de constituir una reacción adaptativa a una situación dada, respecto de la cual se elimina toda opción de hablar en contra. El sujeto así emancipado no cuestiona las fuentes de su sometimiento más que en términos del desequilibrio emocional que producen, y, por tanto, toda emancipación se reduce a evitar los efectos sin conside- rar las causas, promoviendo actitudes que van de la indiferencia a la indolencia, o que oscilan entre el escapismo hedonista hacia nuevas experiencias y una suerte de estoica aceptación ${ }^{5}$.

Ilustremos brevemente estas afirmaciones. El capítulo 8, titulado "La trampa de la justicia" está encabezado por una nota superior, con pretensiones aforísticas, que dice así: "Si el mundo estuviera tan organizado que todo tuviera que ser justo, no habría criatura viviente que pudiera sobrevivir ni un solo día. A los pájaros se les prohibiría comer gusanos, y habría que atender a los intereses personales de todos los seres humanos." (Dyer, 1993, 227). Abordando la cuestión con más detalle, continúa el autor: "Estamos condicionados a buscar justicia en esta vida; y cuando no lo conseguimos sentimos enfado, ansiedad o frustración. En realidad sería igualmente productivo que buscáramos la fuente de la eterna juventud o algún otro mito por el estilo. La justicia no existe. Nunca ha existido y jamás existirá. Simplemente el mundo no ha sido organizado de esa manera. Los gorriones comen gusanos. Eso no es justo para los gusanos. (...) No tienes más que observar la naturaleza para observar que no hay justicia en este mundo. (...) Tú puedes ser feliz o desgraciado, pero esta elección nada tiene que ver con la falta de justicia que veas a tu alrededor. Este no es un punto de vista amargado de la humanidad y del mundo sino más bien un informe realista sobre lo que es el mundo."'. (Dyer, 1993, 228)

Bastan estas declaraciones para estar tentados de resumir groseramente la propuesta con un "cómo sobrevivir en la jungla", imagen que, por otra parte, no anda 
lejos del imaginario popular que produce el orden social neoliberal. Más adelante el autor matiza sus ideas: "La justicia es un mero concepto casi imposible de aplicar, en especial, en lo que se refiere a tus propias opciones de realización y felicidad personales. Pero muchos de nosotros tendemos a exigir que la justicia y equidad sean parte inherente de sus relaciones con los demás. (...) La exigencia de justicia no es un comportamiento neurótico. Sólo se convierte en una zona errónea cuanto te castigas a ti mismo con una emoción negativa al no poder ver la justicia que exiges. En este caso el comportamiento autofrustrante no es la exigencia de justicia, sino la inmovilización que puede generar esa realidad sin justicia. (...) La injusticia es una constante en la vida, pero con la infinita sabiduría que acabas de adquirir puedes decidirte a luchar contra esa injusticia y a negarte a quedar inmovilizado emocionalmente por ello. Puedes trabajar para ayudar a extirpar la injusticia y puedes decidir que no te dejarás vencer psicológicamente por ella." (Dyer, 1993, 228-229).

El argumento subsiguiente declara, pues, que el objeto de tratamiento no es la falta de justicia sino el impacto emocional que ello produce en nosotros. Desde un punto de vista psicológico, -y ya que el autor es psicólogo-, es fácil objetar que en el modo de plantear la determinación a actuar contra la injusticia parecen banalizarse los componentes emocionales que constituyen la motivación para la acción humana, esto es, cabe pensar que difícilmente pueden emprenderse acciones contra la injusticia desde la indolencia. No se ve, por lo demás, qué sentido puede tener para nadie emprender una lucha en pos de algo (la justicia) de lo que previamente se ha dicho que no existe ni existirá jamás. Sea cual fuere la noción de justicia que el autor presupone en cada mención que hace del concepto, resulta evidente que la reflexión sobre los valores y actitudes morales propios está subordinada a la adquisición de actitudes psicológicas exteriormente útiles, o dicho en otras palabras: la constitución de un "yo" psicológicamente adaptado al entorno social elimina, por inconveniente, toda opción de constitución moral individualmente libre. Por tanto, el estoicismo que pudiera vislumbrarse en esta propuesta no es el propio del cultivo de sí que Foucault (2005, 2006 y 2009) analizó en su estudio de los textos antiguos. En aquel $\mathrm{cul}$ tivo de sí, y en aquella "administración del yo", había algo más que la mera protección ante el daño emocional, había una regulación de la acción que no confunde la autonomía con docilidad ni con indolencia, sino que expresa la soberanía que se ha de ejercer sobre los propios actos y actitudes en virtud de una independencia moral que no cede ante las contingencias externas.

Citaremos ahora otro lugar del texto de Dyer, que es parte del capítulo titulado "Explorando lo desconocido", en relación con esa otra tendencia que más arriba hemos mencionado como "escapismo hedonista", dando a entender que no se trata de un hedonismo fundamentado en opciones racionales. Allí declara el autor: "Como eres una persona adulta sientes que tienes que tener una buena razón para hacer las cosas. Esta pasión por las razones evita que te abras y crezcas. Qué libertad da el saber que no tienes que justificarte ante nadie, $n i$ ante ti mismo ${ }^{7}$, nunca más. Puedes hacer 
cualquier cosa que quieras hacer porque lo deseas y por ningún otro motivo. Esta manera de pensar te abrirá nuevas perspectivas de experiencia y te ayudará a eliminar el miedo a lo desconocido."(Dyer, 1993,167).

Se expresa aquí, en un tono ciertamente condescendiente, lo que aparece como una constante en los textos de autoayuda, a saber, una propuesta de autoinspección, autorregulación y autoevaluación de las que debe estar ausente todo intento de justificación moral. Fundamentar la conducta en razones éticas se considera poco saludable psicológicamente. Nada más lejos del antiguo "cuidado de sí" en que la relación con uno mismo es el lugar primordial ante el que se deben rendir cuentas. No siendo así, las inclinaciones y los deseos fácilmente podían esclavizarnos o disponerse a merced de otro, cuyas justificaciones harán las veces de las nuestras. Desde esta perspectiva, el ideal de autonomía aparece en la autoayuda como una construcción flotante, sin sustento alguno en decisiones racionales, pero sí susceptible de adherirse a cualquier otro razonamiento ajeno al nuestro. Se predica aquí una forma de emancipación que suena en principio reconfortante, pero que pronto revela su inconsistencia lógica y ética: autonomía sin racionalidad.

En otro lugar, perteneciente al capítulo "Rompiendo la barrera de los convencionalismos" se dice: "Te es permitido no tener dignidad si así lo escoges. Nadie te está llevando la cuenta ni nadie te va a castigar por no ser algo que otra persona dijo que deberías ser." (Dyer, 1993, 205). En efecto, en el orden social neoliberal nadie en particular nos dice lo que deberíamos ser, y esa es precisamente una de las ra- zones que esgrimen sus entusiastas como prueba de libertad para el individuo. Sin embargo es todo un orden social el que está diciendo más bien qué estamos obligados a ser (o, dicho negativamente, qué se nos exige estar en condiciones de soportar) desde el momento en que su funcionamiento depende de mecanismos que segregan a los individuos en razón de condiciones como el infortunio, la pobreza o la enfermedad que por sí solas representan motivos de exclusión.

\section{Conclusión: autoayuda como emancipación fraudulenta}

Según nuestra lectura de este fenómeno, el discurso de autoayuda contribuye en gran medida al objetivo de que el individuo contemporáneo indague dentro de sí tanto las causas como los remedios paliativos de las múltiples quiebras de la estabilidad socioeconómica y emocional que constituyen el signo de su tiempo. Paradójicamente, la noción de autonomía que articulan en torno suyo los procedimientos autoterapéuticos y "emancipadores" de estos textos está, permitámonos decir, "contaminada" de heteronomía por doquier, en tanto que las fuentes de la emancipación que aquí se prescriben son en realidad modos de subjetivación impuestos por un tipo de racionalidad estatal al que se adjunta como instrumento de gobierno el aparato psicoterapéutico. Estamos, por tanto, ante la conformación de una "subjetividad heterónoma", tal como sugiere $\mathrm{V}$. Papalini en un trabajo que analiza la literatura de autoayuda desde la óptica foucaultiana: "El sujeto es llamado a 'tomar el destino en sus manos', un destino pre- 
figurado socialmente y que deberá modificar con los siempre insuficientes recursos individuales. (...) se puede hablar de la literatura de autoayuda como de un dispositivo ideológico que naturaliza las pautas sociales y los principios rectores de la sociedad capitalista tardía y que ofrece, en consonancia con la clave resolutiva general de esta sociedad, una tecnología como salida a los problemas planteados."(Papalini, 2007, 46).

Desde esta lectura, las "zonas erróneas" del texto de Dyer, no son otra cosa que los aspectos psicológicos del individuo que no están preparados para afrontar dicha situación. Estar preparado es adquirir un cierto modo de autosuficiencia, aquella que evite en lo posible las zonas de fricción con una dinámica económica y social que se sirve de los individuos pero que no puede velar por ellos. Se requiere, en consonancia con esto, un cierto tipo de autoconocimiento para el cual se nos provee de las técnicas precisas, pues el discurso psicoterapéutico, como tecnología de poder que hace al individuo gobernable, presta el servicio ${ }^{8}$ de obligarlo a ser "experto en sí mismo" (Rose, 1997). De la provisión de tales técnicas se encarga en buena parte la autoayuda, funcionando como herramienta textual de una estrategia política.

La sospecha que Foucault había formulado respecto a la insuficiencia ética de nuestra "cultura de sí" no es ajena a quienes estudian la hegemonía actual de lo psicoterapéutico. Aunque estos autores no necesariamente echan de menos los mismos aspectos que Foucault hubiera querido en una ética del cuidado de sí, manifiestan en todo caso la inquietud por cierto menoscabo de la subjetividad desde un punto de vista ético. Así, en conexión con las aspiraciones de esta racionalidad política neoliberal, el análisis de los medios y fines a los que se adhieren las ciencias "psi" revela "la pobreza de la ética psicoterapéutica": "Sea lo que fuere lo que se ganó insistiendo en la autonomía y los derechos de autorrealización, algo se ha perdido (...) Hay un sentido de la escasez ética de la obligación contemporánea de satisfacernos mediante los logros diarios de nuestras vidas, y de evaluar todos los aspectos de las mismas en términos de la medida en que contribuimos o no a tan inexorable trayectoria de automejora y felicidad personal a través de la mejora de nuestra carrera y la maximización del estilo de vida." (Rose, 1999,. xxiv-xv)

Otros autores de orientación foucaultiana aprovechan, en cambio, esta perspectiva del análisis en el sentido más optimista que permite la obra de Foucault. Así, por ejemplo, Petersen y Lupton (1997) concluyen sus repasos a los modos en que actualmente es subjetivado el individuo proponiendo una visión del sujeto menos restrictiva que la de un recipiente pasivo y manipulado. Apoyándose en los últimos escritos de Foucault, dichos autores afirman que la complejidad de las relaciones entre las normas dominantes y las conductas de los individuos deja un margen a un compromiso más "juguetón" con las normas, que puede propiciar formas de resistencia en defensa de la libertad subjetiva. En este sentido, llaman la atención sobre cierto grado de indeterminación y apertura que la idea de la vida como "la empresa de uno mismo" puede sugerir. La exploración teórica de esa zona 
estaría seguramente en consonancia con las motivaciones que Foucault proyectaba desarrollar en la continuación de su obra, una exploración de "los modos de existencia que rompieran con las tendencias "normalizadoras" de la sociedad contemporánea, particularmente, el examen sin fin del interior del yo que él contempló como la característica dominante de la sociedad moderna." (Petersen y Lupton, 1997, 179).

Para nosotros, ese 'examen sin fin del interior del yo" está bien representado en las prácticas y entrenamientos que propone el fenómeno textual de la autoayuda, y es la directriz que preside los esfuerzos del individuo en pos de una emancipación fraudulenta, puesto que más que hacer al sujeto dueño del libre albedrío con que elaborar su dimensión ética y sus opciones existenciales, le hace responsable de las deficiencias que son señaladas como tales por el modelo sociopolítico vigente, y le obliga a ser consciente inde-

\section{REFERENCIAS BIBLIOGRÁFICAS}

Abraham, T. (ed) (1990): "El estado terapéutico", en Christian Ferrer (comp.), El lenguaje libertario 1. El pensamiento anarquista contemporáneo. Editorial Nordan-Comunidad, Montevideo, pp. 185-216.

Abraham, T. (2000): La empresa de vivir, Editorial Sudamericana, Buenos Aires. Ampudia de Haro, F. (2006): “Administrar el yo: literatura de autoayuda y gestión del comportamiento y los afectos". Reis: Revista española de investigaciones sociológicas, $n^{\circ} 113$, pp. 49-72. finidamente de una constitución psico-social defectuosa que ha de aplicarse con urgencia a reparar. En ello advertimos la construcción de una pseudoética que confunde las prescripciones éticas de uno mismo con las prescripciones normalizadoras de un conocimiento psicológico adjunto al poder político.

A pesar de este diagnóstico, es preciso reconocer, en los efectos de los textos de autoayuda, la posibilidad de cierta ambivalencia que hablaría a favor de los aspectos en que estas técnicas pudieran constituir una ayuda valiosa. ${ }^{9}$ En este sentido cabría atender como objeto de ulterior investigación a las posibles relaciones constructivas que el lector pueda mantener con estos textos, relaciones en que el sujeto mantenga la distancia que le permita cuestionarse la identidad y el modelo de vida dichosa hacia los que estas prácticas le orientan, así como salvaguardar su individualidad para sentirse o no vinculado por los medios y fines propuestos.

Cruikshank, B. (1996): "Revolutions within: self-government and self-steem", en Andrew Barry et al. (eds), Foucault and Political Reason, Chicago, The University of Chicago Press, pp. 231-252

De Marinis, P. (1998): "La espacialidad del Ojo Miope del poder", Revista Archipiélago, num. 34/35, pp.32-39

Dyer, W. W. (1993): Tus zonas erróneas, Barcelona, Grijalbo.

Foucault, M. (1988): "El sujeto y el poder", en Dreyfus, H.L. y Rabinow, P., Michel Foucault: más allá del estructuralismo y la hermenéutica, México, Universidad Nacional Autónoma, pp. 227-242. 
Foucault, M. (1990): Tecnologías del yo y otros textos afines, Barcelona, Paidós/I.C.E.- U.A.B.

Foucault, M. (1999): “¿Qué es la Ilustración?”, en Estética, Ética y Hermenéutica, Volumen III de Michel Foucault. Obras esenciales. (pp. 335-352) Barcelona, Paidós.

Foucault, M. (2005): La Hermenéutica del Sujeto. Curso del Collège de France (1982), Madrid, Akal.

Foucault, M. (2006): El cuidado de sí (Historia de la sexualidad, vol. 3), Madrid, Siglo XXI.

Foucault, M. (2009): El uso de los placeres (Historia de la sexualidad, vol. 2), Madrid, Siglo XXI.

Hacking, I. (2002): Historical Ontology, Cambridge Mass; London: Harvard University Press.

Hacking, I. (2006): "Kinds of People: Moving Targets", Bristish Academy Lecture, (web version).

Luchtenberg, E. y Bruno, D. (2006): “Sociedad post-disciplinaria y constitución de una nueva subjetividad. Un análisis de los discursos de 'autoayuda' y del nuevo management desde la perspectiva de Michel Foucault", Nomadas- Revista Crítica de Ciencias Sociales y Jurídicas (13-2006/1) Universidad Complutense de Madrid.

Lupton, D. (1999): Risk, Florence, KY, USA: Routledge.
McGee, M. (2005): Self-Help Inc.: Makeover Culture in American Life, Oxford University Press.

Niesslein, J. (2008): Practically Perfect in Everyway, New York, Penguin Group.

Oestreich, G. (2008): Neostoicism \& the Early Modern State, Cambridge University Press, New York.

Papalini, V. (2007): "La domesticación de los cuerpos", en Revista Venezolana de Información, Tecnología y Conocimiento, Año 4: Num. 1, Enero-Abril 2007, pp. 39-53.

Petersen, A. y Lupton, D. (1997): The New Public Health: Health and Self in the Age of Risk, London, SAGE Publications Ltd.

Rose, N. (1997): "El gobierno en las democracias liberales avanzadas: del liberalismo al neoliberalismo", Revista Archipiélago, Num. 29 pp. 25-40.

Rose, N. (1998): Inventing Ourselves: Psychology, Power and Personhood, Cambridge University Press

Rose, N. (1999): Governing the Soul: The shaping of the private self, New York, Free Association Books.

Sáez, J. (2004): "Internamiento psiquiátrico", en Román Reyes (dir.): Diccionario crítico de Ciencias Sociales, Madrid, publicación electrónica de la Universidad Complutense.

Sennet, R., (2000): La corrosión del carácter, Barcelona, Anagrama. 
¿Hacia qué fines nos orientan los textos de autoayuda?: Una reflexión desde el concepto foucaultiano...

NOTAS

1 "Pensamos -escribe Ian Hacking- en muchos tipos de personas como objetos de investigación científica. A veces para controlarlos, como a las prostitutas, veces para ayudarlos como a potenciales suicidas. (...) A veces para cambiarlos por su propio bien y por el bien público como a los obesos. A veces para admirarlos, comprenderlos, animarlos y quizá imitarlos como a los genios. Pensamos estos tipos de personas como clases determinadas definidas por determinadas propiedades. Cuanto más sepamos sobre esas propiedades, mejor podremos controlarlos, cambiarlos, ayudarlos o imitarlos. (...) A veces nuestras ciencias crean tipos de personas que en cierto modo no existían antes. Llamo a esto 'inventar personas'. (Hacking,2006, 2)

${ }^{2}$ En opinion de Cruikshank, esta situación puede entenderse como un legado del pensamiento de Tocqueville que, -a su juicio-, entendió la democracia como un tipo de sociedad más que como forma de gobierno.

${ }^{3}$ En referencia a Gloria Steinem, autora de un bestseller de autoayuda titulado Revolution within: a book of Self-Esteem, 1992, London, Little Brown.

${ }^{4} \mathrm{La}$ oferta de psicoterapia en nuestro país ha empezado a ser regulada como parte de los servicios de salud pública en los últimos años, para ciertos casos y según derivación por parte del médico de familia. Se observa un aumento en la tendencia a solicitar estos servicios por parte del paciente a través de estos cauces (Información proporcionada por la Unidad de Docencia y Psicoterapia del Hospital Virgen de las Nieves de Granada). Sin embargo, la mayor demanda de estos servicios se produce en el sector privado, -por parte de quienes pueden hacer frente al coste económico que representan-, sector en que es posible elegir la orientación psicológica de los tratamientos y recibir atención en esquemas horarios más flexibles.

${ }^{5}$ Conviene aquí recordar dos anotaciones. Una es la que se refiere a la resonancia estoica que puede atri- buirse a la idea de "administración del yo" que caracteriza, según algunos autores, a la función de los textos de autoayuda como prácticas o tecnologías de sí mismo (Ampudia de Haro, 2006). La otra anotación se refiere a las influencias neoestoicas a la luz de las cuales Oestreich (2008) analiza las nuevas formas de poder y administración que producen los estados modernos, así como el concepto de disciplina internalizada en el sujeto que deriva históricamente de dichas formas.

${ }^{6}$ Aunque la reflexión sobre las diversas filiaciones e inconsistencias éticas implícitas en los discursos de autoayuda merecería un estudio específico, digamos al menos en este punto que la propuesta de la naturaleza como modelo de interacción entre los individuos incurre en lo que la tradición filosófica ha denominado, -a partir de los análisis de David Hume , "la falacia naturalista", que consiste en deducir enunciados prescriptivos a partir de enunciados descriptivos. En ese orden de extrapolación infundada, el autor extrae consideraciones sobre lo que "deben" ser las cosas en el ámbito de la conducta humana a partir de lo que "son" en el orden de interacción de la naturaleza.

${ }^{7}$ Cursiva nuestra.

${ }^{8}$ Esta expresión no significa que los discursos psicoterapéuticos o de otro tipo funcionen como una especie de "siervos del poder". Es sabido que desde la perspectiva foucaultiana la noción de "poder" no se entiende como dinámica explotador-explotado, o como forma de violencia instrumental, pues "el poder no es más que un tipo peculiar de relaciones entre individuos" (Foucault, 1990, 138) y "el gobierno de los hombres por los hombres supone cierta forma de racionalidad y no de violencia instrumental.” (Foucault, 1990,139)

${ }^{9}$ El libro de Jennifer Niesslen(2008) titulado Practically perfect in every way, es una muestra de esta ambivalencia percibida desde la experiencia del usuario de textos de autoayuda. 